\title{
SELF COMPACTING CONCRETE FOR SLIP FORM PAVING
}

\author{
Prabhakar Havalagi ${ }^{1}$, Ashwin M Joshi' ${ }^{2}$ Arjun H R ${ }^{3}$ \\ ${ }^{1}$ Former M. Tech Student, Department of ICM, RASTA - Center for Road Technology, Bangalore 560058 \\ ${ }^{2}$ Assistant Professor, Department of ICM, RASTA Center for Road Technology, Bangalore 560058 \\ ${ }^{3}$ Assistant Professor, Department of Civil Engineering, Christ University, Bangalore 560074
}

\begin{abstract}
Slip form paving has been extensively used worldwide for construction of pavements. During the process of paving, concrete mix with a slump less than $50 \mathrm{~mm}$ is placed in front of a paver. Because of the low consistency of the mix, a great deal of vibration is needed to move entrapped air and compact the concrete. There is a need to overcome problem by designing a concrete that would not require vibration to compact the concrete mix, at the same time stability after extrusion and high flexural strength. Mix design based on the absolute volume concept was adopted to fabricate SFSCC. Volume of paste of 0.38 and water content of $200 \mathrm{~kg} / \mathrm{m}^{3}$ was kept constant throughout the study. Cement content was varied from 360 to $425 \mathrm{~kg} / \mathrm{m}^{3}, 3$ mixes of SCC with GGBS (SFSCCS), 3 mixes of SCC with $2 \%$ of alccofine replaced by cement (SFSCC-SA) and 3 mixes of SCC with $2 \%$ of metakaolin replaced by cement (SFSCC-SM) is reported. The quantity of polypropylene fibers used in all the mixes was $900 \mathrm{gm} / \mathrm{m}^{3}$. Slump, spread, green strength and compaction factor were evaluated for all the 9 mixes. To simulate the practical construction process, a mini paver system was fabricated. The strength parameters compressive and flexural strength of concrete was evaluated at 7 days and 28 days.
\end{abstract}

Keywords: Slip form paving, alccofine, SCC, GGBS, metakaolin, SFSCC, SP.

\section{INTRODUCTION}

Slip form paving has been extensively used worldwide for construction of pavements by the industry. Unlike the 'fixed form paving', slip-form paver usually performs screeding, consolidation and finishing (initial). A typical "track mounted, self propelled paver" operates at operating speed ranging from 1 and $2.5 \mathrm{~m} /$ minute. First an auger spreads the PCC in front of the strike off plate. Second, the strike off plate removes excess portions of auger-placed PCC and brings the slab near its final elevation. Third, the PCC is consolidated group of vibrators. Forth, a tamper pushes large aggregate particles below the slab surface. Finally, the profile pans level off at the right elevation and provide initial finishing. After extrusion, the fresh concrete slab can hold in shape without any lateral support for further finishing of surface, texturing of surface and curing until the concrete sets. Because of the low consistency of the mix, a great deal of vibration is needed to remove entrapped air, consolidate the concrete and reduce longitudinal trails and segregation in cement concrete pavement.

Recent research has demonstrated that the concept of self compacting concrete (SCC) can be used to design a special concrete that not only can self compact but also hold it shape right after casting. Such a special concrete is of a great potential for slip form (SF) construction and hence it is therefore called SFSCC. A relatively new self compacting concrete for slip-form application (SFSCC) would permit the concrete paving industry to have not only more uniform, durable, and smoother pavements but also much faster, safer, and quieter construction. Such concrete could also be applied to slip form construction of many other structures, such as water towers, silos and water tanks.

\section{LITERATURE REVIEW}

Concept of SCC was proposed by Professor Hajime Okamura of Japan, in 1986 as a solution to the growing durability concerns of the Japanese government. During his research, Okamura [1] found that the main cause of the poor durability performances of Japanese concrete in structures was the inadequate consolidation of the concrete in the casting operations. By developing concrete that selfconsolidates, he eliminated the main cause for the poor durability performance of their concrete. At similar water/cement ratios, the characteristics strength of SCC is at least equal to that of traditional concrete, and has similar strength development for the same grade. Bouzoubaa and Lachemi [2] noticed that higher split tensile strength and lower modulus of elasticity was obtained from SCC mixtures when compared with normal vibrated concrete. Zhu et al. [3] confirmed that SCC cast-in situ could prove similar (or even better) uniformity in key properties compared to those obtained with properly compacted traditional concrete. Kejin Wang et al. [4] reported that, the addition of metakaolinite clay is most beneficial when used in an additive amount of $1.5 \%$ of Cement. As metakaolin percentage increases green strength decreases. Kejin Wang et al. [5] studied 7 and 28 days compressive strength of SFSCC, the compressive strength of SFSCC mixes has higher than that of the Conventional paving concrete. This is mainly due to the lower w/c ratios. Slamet Widodoet al. [6] studied the fresh and hardened properties, monofilament polypropylene with $18 \mu \mathrm{m}$ diameter, and $12 \mathrm{~mm}$ length. Concrete mixes were added with polypropylene fiber of $0 \%$, $0.05 \%, 0.10 \%$, and $0.15 \%$ volume fraction. Tests results indicate that polypropylene fibers tend to reduce the flowability and passing ability but will increase viscosity 
and segregation resistance of SCC. Shah et al [7] studied the effect of polypropylene addition; the addition rate tested was $0.1 \%$ in percent of the total volume of the concrete. Different amounts of water/cement ratios were investigated, according to the results of the drop table and the green strength tests; the mix that gives the best results is the one with a water/cement ratio of 0.41 . This mix was considered for present study. Deepthy Raja Gopal et al [8] studied the durability characteristics of Self-Compacting concrete using Manufactured Sand. M 35 mix was designed using Master Glenium Sky 8233 as chemical admixture and Fly Ash as additive. Pamnani et al [9] studied self curing self compacting concrete (SCSCC) using Polyethylene Glycols (PEGs). The effect on compressive strength of M30 grade SCSCC was discussed and compared with same grade of SCC with conventional immersion curing and dry curing technique.

\section{EXPERIMENTAL STUDY}

\subsection{Materials}

Ordinary Portland cement (OPC 53grade) conforming to Indian standard specifications IS: 12269-1987 [11] was used. Ground Granulated Blast Furnace Slag (GGBS), Alccofine and Metakaolin were used and their specific gravity was 2.8, 2.8 and 1.9 respectively. Locally available natural sand and manufactured sand with $4.75 \mathrm{~mm}$ maximum size was used as fine aggregate and crushed stone with $20 \mathrm{~mm}$ maximum size was used as coarse aggregate. The properties of fine aggregate and coarse aggregate were found to conform to IS: $383-1970$ [12]. Its physical properties are given Table 1 and 2 [15]. Polypropylene fibers of length $12 \mathrm{~mm}$ were used. Polycarboxylic ether based SP (super plasticizer) complying with IS: 9103-1999 [13] was used.

Table 1: Physical properties of natural sand and manufactured sand

\begin{tabular}{|l|l|l|l|}
\hline $\begin{array}{l}\text { SI } \\
\text { No }\end{array}$ & Details & $\begin{array}{l}\text { Natural } \\
\text { Sand (NS) }\end{array}$ & $\begin{array}{l}\text { Manufactured } \\
\text { Sand (MS) }\end{array}$ \\
\hline 1 & Specific Gravity & 2.61 & 2.49 \\
\hline 2 & Water Absorption (\%) & 1.50 & 4.20 \\
\hline 3 & Fineness Modulus & 2.78 & 2.48 \\
\hline 4 & $\begin{array}{l}\text { Loose Bulk Density } \\
\left(\mathrm{kg} / \mathrm{m}^{3}\right)\end{array}$ & 1536 & 1581 \\
\hline 5 & Passing 75 $\mu(\%)$ & 0.00 & 9.10 \\
\hline
\end{tabular}

Table 2: Physical properties of Coarse aggregate

\begin{tabular}{|l|l|l|}
\hline Sl. No & Details & Results \\
\hline 1 & Specific Gravity & 2.65 \\
\hline 2 & Water Absorption $(\%)$ & 0.30 \\
\hline 3 & Loose Bulk Density $\left(\mathrm{kg} / \mathrm{m}^{3}\right)$ & 1290 \\
\hline
\end{tabular}

\subsection{Mix Design Procedure}

Mix design can be defined as the process of selecting suitable ingredients of concrete and determining their relative proportions with the object of producing concrete of certain minimum strength and durability as economically as possible. Aggregate and cement paste are the two essential ingredients of concrete.

As per IRC: 15 - 2011 [14], the minimum cement [17] content should be $360 \mathrm{~kg} / \mathrm{m}^{3}$ and the maximum cement content should be $425 \mathrm{~kg} / \mathrm{m}^{3}$. The SCC mixes (Girish et al [10]) can be developed by taking the volume of paste (i.e., sum of volume fractions of cement, filler and water) with a mean value of 0.38 with a variation of \pm 0.03 barring few mixes. Exceptions are seen, since, flowability is of about also influenced by aggregate shape, gradation of sand, type and amount of superplasticizer used. In most of the SCC mixes arrived in India it is observed that the fine aggregate volume is predominantly more compared with the coarse aggregate volume. The paste volume used is generally higher due to angular crushed aggregate which demand more amount of water to coat the surface of aggregates.

It is possible to proportion SCC mixes for a given strength and flowability by keeping the paste content constant and by increasing or decreasing the filler content vis- à-vis the cement. Keeping all other parameters constant and only by changing the amount and filler quantities with in a constant paste volume, different grades of concrete can be arrived at and a mix design method in the lines of the absolute volume method can be evolved.

The mix was designed to achieve a target compressive strength - 40MPa. Mix design method adopted was by starting with a fixed volume of paste $\left(\mathrm{V}_{\mathrm{p}}=\mathrm{V}_{\text {cement }}+\mathrm{V}_{\text {flyash }}+\right.$ $\mathrm{V}_{\text {water }}+\mathrm{V}_{\mathrm{sp}}$ ). Further the water was fixed at 200 liters $/ \mathrm{m}^{3}$ (based on trail mix) for SFSCC. Based on past literature, paste content of (about) 0.38 was chosen; volume of cement and GGBS was calculated by keeping the water constant. The cement content considered was $360,390,425 \mathrm{~kg} / \mathrm{m}^{3}$. Correspondingly the volume of GGBS was calculated based on the absolute volume for the fixed paste content and the chosen cement content.

Taking the total volume of concrete as one unit, the final volume of aggregates can be calculated by deducting the volume of paste from the unit volume. Based on the literature survey and the experience with the materials used in the laboratory, the ratios of Coarse Aggregate and Fine Aggregate can be fixed. The optimum dosage of superplasticizers was decided by conducting the trail mixes.

The details of various mix proportions used in the present study are presented in Table 3 for reference. Table consists of details of proportion of various materials such as Cement; GGBS; Aggregates (coarse \& fine); Alccofine; Metakaolin. 
Table 3: Representing the different Mixes used in the present study

\begin{tabular}{|c|c|c|c|c|c|c|c|c|c|c|c|c|c|}
\hline Mix & & $\begin{array}{l}\mathrm{C} \\
(\mathrm{Kg})\end{array}$ & $\begin{array}{l}\mathrm{S} \\
(\mathrm{Kg} / \mathrm{m} 3)\end{array}$ & $\begin{array}{l}\mathbf{A} \\
(\mathbf{K g})\end{array}$ & $\begin{array}{l}\mathbf{A} \\
\%\end{array}$ & $\begin{array}{l}\mathbf{M} \\
(\mathbf{K g})\end{array}$ & $\begin{array}{l}\text { M } \\
\%\end{array}$ & $\begin{array}{l}\text { W } \\
(\mathbf{K g})\end{array}$ & $\begin{array}{l}\text { CA } \\
(\mathbf{K g})\end{array}$ & $\begin{array}{l}\text { NS } \\
\text { (Kg) }\end{array}$ & $\begin{array}{l}\text { MS } \\
\text { (Kg) }\end{array}$ & $\begin{array}{l}\text { Ad } \\
(\%)\end{array}$ & $\begin{array}{l}\mathbf{F} \\
(\mathbf{K g})\end{array}$ \\
\hline M1 & \multirow{3}{*}{ SFSCC-S } & 360 & 184 & - & - & - & - & 200 & 821 & 405 & 386 & 0.16 & 0.9 \\
\hline M2 & & 390 & 157 & - & - & - & - & 200 & 821 & 405 & 386 & 0.165 & 0.9 \\
\hline M3 & & 425 & 126 & - & - & - & - & 200 & 821 & 405 & 386 & 0.17 & 0.9 \\
\hline M4 & \multirow{3}{*}{ SFSCC-SA } & 353 & 184 & 7 & 2 & - & - & 200 & 821 & 405 & 386 & 0.16 & 0.9 \\
\hline M5 & & 382 & 157 & 8 & 2 & - & - & 200 & 821 & 405 & 386 & 0.165 & 0.9 \\
\hline M6 & & 416 & 126 & 9 & 2 & - & - & 200 & 821 & 405 & 386 & 0.17 & 0.9 \\
\hline M7 & \multirow{3}{*}{ SFSCC-SM } & 353 & 184 & - & - & 7 & 2 & 200 & 821 & 405 & 386 & 0.16 & 0.9 \\
\hline M8 & & 382 & 157 & - & - & 8 & 2 & 200 & 821 & 405 & 386 & 0.165 & 0.9 \\
\hline M9 & & 416 & 126 & - & - & 9 & 2 & 200 & 821 & 405 & 386 & 0.17 & 0.9 \\
\hline
\end{tabular}

\begin{tabular}{|l|l|l|l|l|l|l|l|}
\hline C & Cement & Ad & Admixture & M & Metakaolin & CA & Coarse Aggregate \\
\hline S & Slag & F & Fibre (Polypropylene) & NS & Natural Sand & MS & Manufactured Sand \\
\hline A & Alccofine 1203 & W & Water & \multicolumn{4}{l}{}
\end{tabular}

\section{TEST METHODS}

\subsection{Modified Slump Test}

The modified slump cone test that is used for conventional SCC can also be applied. A fresh concrete mix is placed into the slump cone from a constant height $(30 \mathrm{~cm})$ without any rodding, check slump, spread, and shape of the mix right after the slump cone mould is removed. The measurements of the concrete slump and spread are related to the concrete flowability, while the shape of the mix after the slump cone removal provides an insight into the concrete compactability. Figure 1 shows modified slump test.
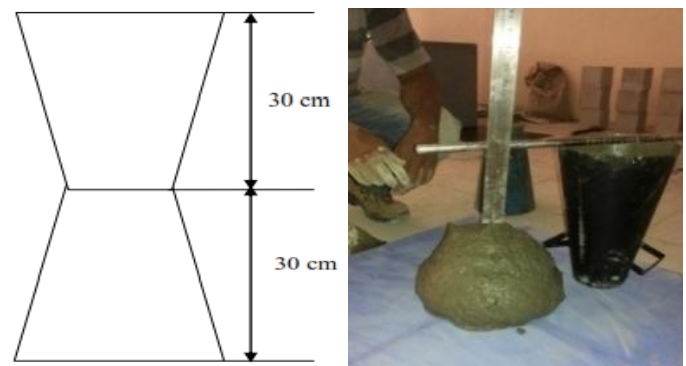

Fig 1: Modified Slump Test

\subsection{Green Strength Test}

In this test, a plastic cylinder mould [10 by $10 \mathrm{~cm}$ ] (without bottom) was used for concrete casting. During the casting, a concrete mix was placed into the cylinder mould at a given height $(30 \mathrm{~cm})$ with no additional compaction. Immediately after the cylinder was filled up, the plastic mould was removed, and the shape of the concrete sample was examined and the green strength test of the sample was then pursued. A large plastic cylinder was placed on the top of the fresh concrete sample. A small amount of sand was then slowly but continuously poured into the large plastic cylinder until the sample collapsed. The maximum amount of the sand applied during the test divided by the loading area of the sample defined the green strength of the concrete. Figure 2 shows green strength test.

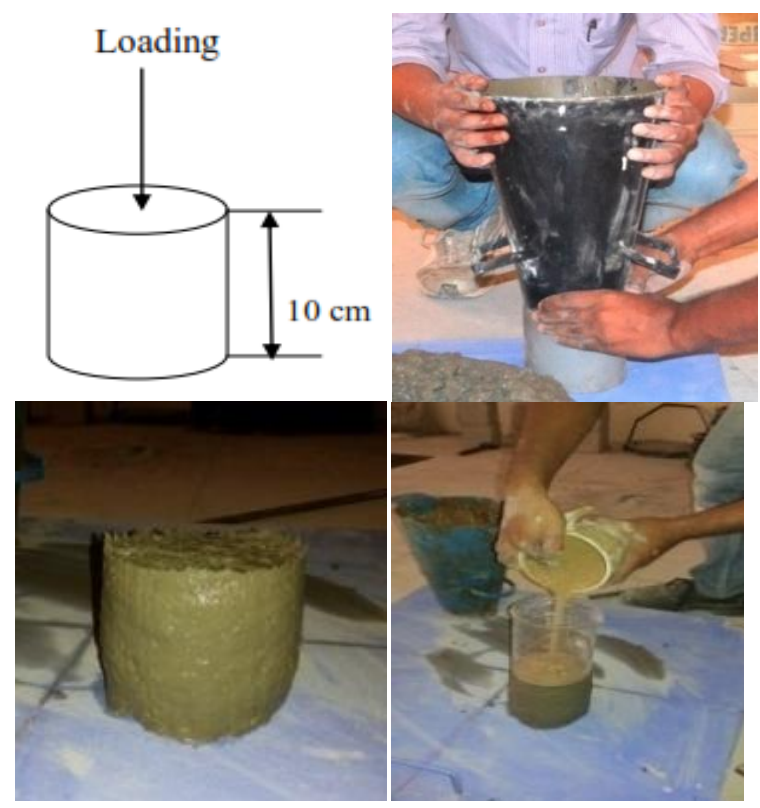

Fig 2: Green Strength Test

\subsection{Mini-Paver Tests}

A mini-paver was developed to simulate field paving using SFSCC in laboratory. The system consisted of two parts: (1) L-box with a platform on top, (2) a working table. The Lbox was $46 \mathrm{~cm}$ wide, $60 \mathrm{~cm}$ long, $46 \mathrm{~cm}$ high and $15 \mathrm{~cm}$ thick. It could pave a $46 \mathrm{~cm}$ (wide), $15 \mathrm{~cm}$ (thick), and 90 $\mathrm{cm}$ (long) slab in the lab using 0.06 cubic meter of concrete mix, mini paver system shown in figure 3 . 
Before the paving test, approximately $90 \mathrm{~kg}$ of weights were placed in the back chamber of paver; a stop plate was positioned at end of the horizontal leg of the L-box. Freshly mixed concrete was stored on platform. To begin paving, concrete was pushed from the platform into the vertical leg of the L-box up to a certain height, which generates pressure to consolidate concrete. Then, the mini-paver pulled forward at a designed speed $(0.9$ to $1.5 \mathrm{~m} / \mathrm{min})$. As the mini-paver moved forward, it extruded the concrete slab out of the horizontal leg of the L-box.

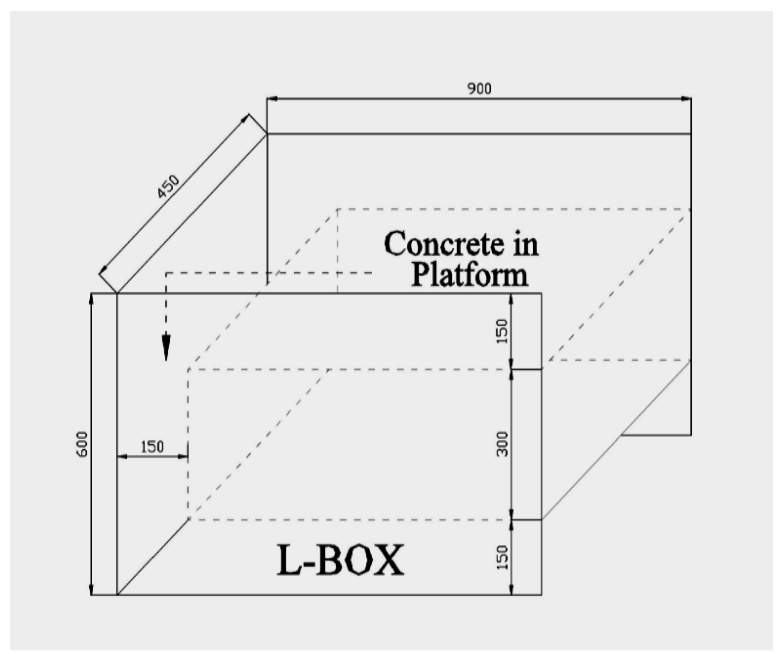

Fig 3: Mini Paver System

\section{RESULTS AND DISCUSSION}

The results and discussions are done on SFSCC-S, SFSCC$\mathrm{SA}$ and SFSCC-SM mixes.

In concrete mix design procedure, the volume of paste considered in the present study was 0.38 . The quantities of cement considered were $360,390,425 \mathrm{~kg} / \mathrm{m}^{3}$ for SFSCC-S, SFSCC-SA, SFSCC-SM. water content of $200 \mathrm{~kg} / \mathrm{m}^{3}$ was fixed based on the trails the ratio of fine aggregate and coarse aggregate was taken as 50:50 and in fine aggregate, $50 \%$ natural sand and manufactured sand was adopted based on the initial trails.

The cubes and beams were tested for SFSCC-S, SFSCC-SA, SFSCC-SM mixes at 7 and 28 days.

\subsection{Modified Slump Test}

Table 4: Slump and Spread Results

\begin{tabular}{|c|c|c|c|c|}
\hline Mix & & $\begin{array}{l}\text { Cement } \\
\left(\mathrm{kg} / \mathrm{m}^{3}\right)\end{array}$ & $\begin{array}{l}\text { Slump } \\
(\mathbf{m m})\end{array}$ & $\begin{array}{l}\text { Spread } \\
(\mathbf{m m})\end{array}$ \\
\hline M1 & \multirow{3}{*}{ SFSCC-S } & 360 & 165 & 285 \\
\hline M2 & & 390 & 155 & 270 \\
\hline M3 & & 425 & 150 & 260 \\
\hline M4 & \multirow{3}{*}{ SFSCC-SA } & 360 & 195 & 320 \\
\hline M5 & & 390 & 170 & 305 \\
\hline M6 & & 425 & 160 & 270 \\
\hline M7 & SFSCC-SM & 360 & 180 & 285 \\
\hline
\end{tabular}

\begin{tabular}{|l|l|l|l|l|}
\hline M8 & & 390 & 175 & 275 \\
\cline { 4 - 5 } M9 & 425 & 160 & 270 \\
\hline
\end{tabular}

Table 4 gives the slump and spread results of SFSCC-S, SFSCC-SA, SFSCC-SM mixes. It can be seen that as cement content increases the slump and spread of SFSCC-S, SFSCC-SA, SFSCC-SM decreases, which indicates the need of finer material than cement for better workability; Indicating improved cohesion in matrix with increased cement content at constant water content. Slump and spread value is higher for SFSCC-SA mix compared to SFSCC-S and SFSCC-SM mixes.

\subsection{Green Strength}

Table 5: Green Strength Results for SFSCC-S

\begin{tabular}{|c|c|c|c|}
\hline Mix & & $\begin{array}{l}\text { Cement } \\
\left(\mathrm{kg} / \mathrm{m}^{3}\right)\end{array}$ & $\begin{array}{l}\text { Green } \\
\text { Strength } \\
(\mathrm{kPa})\end{array}$ \\
\hline M1 & \multirow{3}{*}{ SFSCC-S } & 360 & 1.53 \\
\hline M2 & & 390 & 1.86 \\
\hline M3 & & 425 & 2.15 \\
\hline M4 & \multirow{3}{*}{ SFSCC-SA } & 360 & 1.39 \\
\hline M5 & & 390 & 1.56 \\
\hline M6 & & 425 & 1.77 \\
\hline M7 & \multirow{3}{*}{ SFSCC-SM } & 360 & 1.91 \\
\hline M8 & & 390 & 2.24 \\
\hline M9 & & 425 & 2.57 \\
\hline
\end{tabular}

Table 5 gives the green strength of SFSCC-S, SFSCC-SA, and SFSCC-SM. as cement content increases the green strength increases, presence of alccofine in SFSCC-SA mixes shows decrease in green strength (increases the flowability) compared to SFSCC-S and SFSCC-SM. Green strength value is higher for SFSCC-SM mixes as there is increased density of the concrete mix due to fine particles; Addition of metakaolin improves shape stability, low shape stability concrete mix changed into a non-flowable highly stable mix.

\subsection{Mini Paver Test}

The mini paver test has done for all the mixes, the extruded slab had good stability and surface finish for SFSCC-SM mixes compared SFSCC-S and SFSCC-SA mixes. M9 mix has higher stability and better surface finish compared to all the mixes. Slump has checked at the edges of extruded slab for all the mixes, SFSCC-SM mixes has lower slump value compared to SFSCC-S and SFSCC-SA mixes. 


\subsection{Compressive Strength}

Table 6: Compressive Strength results

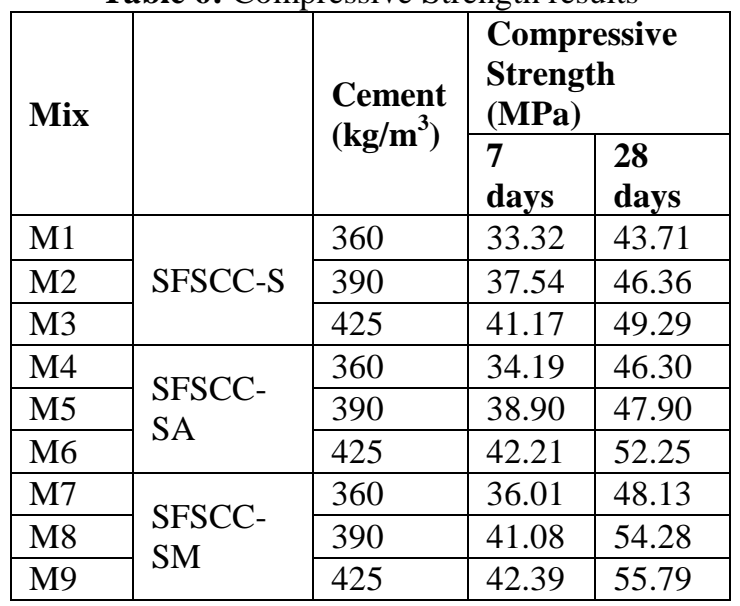

Table 6 represents compressive strength [16] of SFSCC-S, SFSCC-SA and SFSCC-SM at 7 and 28 days. The compressive strengths of SFSCC-SM mixes have higher compared to SFSCC-S, SFSCC-SA mixes, it can be seen that as the cement content increased the strength increased. At the early stage, pozzolanic reactions of GGBS were not sufficient, but at 28 days it has played a part in GGBS mixes. The other two mixes have shown better performance due to physical nature of better packing due to fineness and puzzolonic reaction.

\subsection{Flexural Strength}

Table 7: Flexural strength results for SFSCC-S

\begin{tabular}{|c|c|c|c|c|}
\hline \multirow{2}{*}{ Mix } & & \multirow{2}{*}{$\begin{array}{l}\text { Cement } \\
\left(\mathrm{kg} / \mathrm{m}^{3}\right)\end{array}$} & \multicolumn{2}{|c|}{$\begin{array}{l}\text { Flexural } \\
\text { Strength (MPa) }\end{array}$} \\
\hline & & & 7 days & $\begin{array}{l}\mathbf{2 8} \\
\text { days } \\
\end{array}$ \\
\hline M1 & \multirow{3}{*}{ SFSCC-S } & 360 & 3.07 & 5.73 \\
\hline M2 & & 390 & 3.47 & 6.00 \\
\hline M3 & & 425 & 4.07 & 6.30 \\
\hline M4 & \multirow{3}{*}{ SFSCC-SA } & 360 & 3.27 & 5.80 \\
\hline M5 & & 390 & 3.67 & 6.00 \\
\hline M6 & & 425 & 4.40 & 7.27 \\
\hline M7 & \multirow{3}{*}{ SFSCC-SM } & 360 & 4.33 & 6.00 \\
\hline M8 & & 390 & 4.86 & 7.80 \\
\hline M9 & & 425 & 5.86 & 8.40 \\
\hline
\end{tabular}

Table 7 represents flexural strength [16] of SFSCC-S, SFSCC-SA and SFSCC-SM at 7 and 28 days. SFSCC-SM mixes have higher flexural strength compared to SFSCC-S, SFSCC-SA mixes and as the cement content increased the strength increased. Alccofine and metakaolin mixes have shown better performances.

\section{CONCLUSION}

Within the scope of experimental investigations carried out, the following conclusions were drawn.

1) Mix design based on the absolute volume concept starting with a volume of paste can be successfully used to fabricate
SFSCC. The method reduces the number trials for achieving the desired fresh properties.

2) Slump value (and spread value) is higher for SFSCC-SA mix compared to SFSCC-S and SFSCC-SM mixes, as cement content increases the slump and spread increases in all mixes.

3) As cement content increases the green strength increases, green strength is higher for SFSCC-SM mix compared to SFSCC-S and SFSCC-SA mixes.

4) Compaction factor value is more than 0.98 for all the mixes.

5) For Mini paver test, SFSCC-SM mixes showed better stability and surface finish compared to SFSCC-S and SFSCC-SA mixes.

6) The compressive strength and flexural strength of SFSCC-SM mixes is higher than the SFSCC-S and SFSCCSA mixes.

\section{ACKNOWLEDGEMENTS}

The authors would like to thank Christ University for providing opportunity to carryout this work.

\section{REFERENCES}

[1]. Hajime Okamura et al, "Self Compacting Concrete (Invited Paper)", journal of advanced concrete technology volume 1, No 1, April 2003, pp 5-15

[2]. N Bouzoubaa, M Lachemi, "Self Compacting Concrete Incorporating High Volumes of Class Fly Ash Preliminary Results", Cement and Concrete Research, Volume 31, 2001, pp $413-420$

[3]. Zhu W and Bartos, "Permeation Properties of SCC", Cement and Concrete Research, Volume 33, No 36, 2003, pp $921-926$

[4]. Kejin Wang et al, Self consolidating concrete applications for slip-form paving: phase I (feasibility study) Final Report", November 2005

[5]. Kejin Wang, Surendra P Shah and Thomas Voigt: "SelfConsolidating Concrete for slip form construction: Properties and test methods", Advances in Civil Engineering Materials; The $50^{\text {th }}$ year teaching and research anniversary of Prof. Sun Wei, 15 October, Nanjing, China 2008

[6]. Slamet Widodo et al, "Fresh and Hardened Properties of Polypropylene Fiber Added Self-Consolidating Concrete", International Journal of Civil and Structural Engineering, Volume 3, No 1, 2012

[7]. Prof Surendra Shah, Jean-Juste Mbele, "Design and Application of Low Compaction Energy Concrete for Use in Slip-form Concrete Paving", north western University, 2005 [8]. Deepthy Raja Gopal et al, "Durability Study of SelfCompacting Concrete using Manufactured Sand", IJRET, Volume 2, Issue 9, September 2014, pp 41 - 46

[9]. Prof Pamnani Nanak J et al, "Self Curing Self Compacting Concrete: A Sustainable Avenue of Making Concrete", JIARM, Volume 2, Issue 1, February 2014, pp 112 - 123

[10]. S Girish, Jagadish Vengala and R V Ranganath, "Volume fractions in Self compacting concrete - A Review", Fifth International RILEM symposium on Self Compacting Concrete, September 2007, pp 3 - 5 
[11]. IS: 12269 - 1987 - "Specification for 53 grade Ordinary Portland Cement", Bureau of Indian Standard, New Delhi

[12]. IS: 383 - 1970 - "Specification for coarse and fine aggregate from natural sources for concrete", Bureau of Indian Standard, New Delhi

[13]. IS: 9103 - 1999 - "Specifications for concrete admixtures", Bureau of Indian Standards, New Delhi [14]. IRC: 15 - 2011, "Standard Specifications and code of practice for Construction of Concrete Roads", 4th Revision, Indian Roads Congress, New Delhi

[15]. IS: 2386 - 1963 - "Methods of test for aggregate for concrete", Bureau of Indian Standards, New Delhi

[16]. IS: 516 - 1959 - "Methods of tests for strength of concrete", Bureau of Indian Standards, New Delhi

[17]. IRC: 44 - 2011, "Guidelines for cement concrete mix design for pavements”, Indian Roads Congress, New Delhi 